\title{
Profissão acadêmica e scholarship da docência: novo olhar sobre as múltiplas funções do professor universitário
}

\author{
José Camilo dos Santos Filho \\ Carmen Lúcia Dias
}

Resumo: O reconhecimento da qualidade do trabalho docente em atividades não diretamente relacionadas à pesquisa e a crescente exigência da sociedade por uma contribuição mais relevante da universidade para a solução de seus problemas prementes levaram à busca de superação da visão tradicional de scholarship. Neste trabalho, primeiro, o entendimento clássico de scholarship e as propostas de expansão deste conceito por alguns teóricos são apresentados. Em seguida, são analisados o conceito de scholarship da docência e seus componentes básicos. Por último, são citadas algumas propostas e iniciativas introduzidas por universidades para consolidar a scholarship da docência, explicitando suas múltiplas perspectivas e formas concretas de estímulo à sua efetivação prática.

Palavras-chave: Profissão acadêmica. Scholarship da docência. Professor de universidade. Docência universitária. Trabalho acadêmico.

Academic profession and scholarship of teaching: new look at the multiple functions of university professor

Abstract: The recognition of teaching work quality in activities not directly related to research and the growing society requirement for a more relevant contribution of the university to the solution of its urgent problems led to the search for overcoming the traditional understanding of scholarship. In this paper first the classical understanding of scholarship and the expansion proposals of this concept by some specialists are presented. Then the concept of scholarship of teaching and its basic components are analyzed. Finally, some proposals and initiatives introduced by universities for consolidating the scholarship of teaching are cited, making explicit its multiple perspectives and concrete forms of stimulus to its practical implementation.

Key words: Academic profession. Scholarship of teaching. University professor. University teaching. Academic work. 


\section{Introdução}

A profissão acadêmica, em razão das transformações da universidade no decorrer do século XX, veio passando por uma expansão de tarefas e ao mesmo tempo por uma crise crescente em decorrência de sua vinculação privilegiada à primeira revolução da universidade moderna com a introdução da pesquisa como sua principal função ou missão. A prioridade da pesquisa na universidade levou os docentes a privilegiarem as atividades a ela relacionadas, especialmente em decorrência dos critérios adotados para possibilitar o ingresso, a ascensão e a estabilidade na carreira acadêmica. Fenômeno semelhante está ocorrendo com as universidades brasileiras neste início de século XXI (SEVERINO, 2009).

No entanto, o reconhecimento da qualidade do trabalho docente em outras atividades da vida universitária e a crescente exigência da sociedade por uma contribuição mais relevante da universidade para a solução de seus problemas prementes levaram à busca de superação da visão tradicional de scholarship assumida pela universidade desde o século XIX, embora com matizes diferenciados na Inglaterra, na Alemanha e nos Estados Unidos. Como observou em 1906 Lyman Abbott, um clérigo e editor inglês bem conhecido na época, a universidade inglesa considerou a scholarship "como um meio de auto-desenvolvimento" - a formação cultural, a formação de aristocratas gentis-homens -, "a universidade alemã considerou-a como "um fim em si mesmo" - a busca do saber por si mesmo, a erudição, a produção de scholars -, enquanto a universidade americana considerou a scholarship "como um equipamento para o serviço" - para os homens ativos de negócios (RUDOLPH, 1962, p. 356). Se essa realidade acadêmica foi estimulada e valorizada no decorrer da primeira metade do século XX, a partir da Segunda Guerra Mundial as transformações da universidade e do trabalho do docente universitário levaram a uma progressiva incoerência com os critérios de valorização da carreira acadêmica, a uma crescente desvalorização da atividade propriamente docente e a uma exigente cobrança social da contribuição da universidade para a solução de seus problemas. Em suma, a universidade estava mudando no decorrer do século XX, mas o reconhecimento da scholarship de seus docentes estava restrito ao concebido pela universidade alemã acrescido do enxerto americano. Ou seja, era scholarship o trabalho docente na pesquisa e na pós-graduação acadêmica (Graduate School of Arts and Sciences) e nas escolas profissionais pós-graduadas (Graduate Professional Schools - medicina, a partir de 1910 e as demais, no decorrer do século XX, com suas ênfases na pesquisa básica e aplicada). 
Foi especialmente este contexto acadêmico e social que levou alguns intelectuais docentes americanos a propor uma revisão do conceito de scholarship para fazê-lo incorporar toda a gama de atividades acadêmicas realizadas pelos professores das universidades contemporâneas. A fim de tornar mais claras as implicações e a relevância do conceito de scholarship para as diferentes tarefas do docente e, de modo especial para a atividade docente propriamente dita, apresentamos primeiro o entendimento clássico de scholarship e as propostas de expansão de seu conceito apresentadas por Boyer (1990) e Rice (1991), por Paulsen e Feldman (1995) e por Rice (2002). Em seguida, explicitamos o conceito de scholarship da docência e seus componentes básicos. Por último, focalizamos algumas propostas e iniciativas introduzidas por universidades para consolidar a scholarship da docência.

\section{Conceito e expansão do conceito de scholarship}

Scholarship pode ser definida numa variedade de modos, dependendo do propósito da definição. Assim, para uma grande agência de fomento de pesquisa dos Estados Unidos, a scholarship é definida como toda atividade de pesquisa crítica e sistemática em algum campo de conhecimento e a disseminação dos resultados para a crítica por pares acadêmicos e pelo público mediante a publicação de relatórios, palestras ou outros modos de divulgação. A scholarship também é concebida como detendo três características chaves: deve ser pública, susceptível a revisão crítica e avaliação e acessível para troca e uso por outros membros da comunidade acadêmica (SHULMAN, 1998).

Essas definições são muito pragmáticas e são úteis aos órgãos de fomento à pesquisa na escolha e avaliação de resultados de pesquisa. Contudo, scholarship pode ser entendida a partir de dois outros pontos de vista alternativos, mais pertinentes ao contexto intelectual e acadêmico. Shulman (1987) distingue uma scholarship polêmica de uma scholarship acadêmica. A primeira é uma forma de scholarship que promove uma posição particular do autor, especificamente delineada para avançar uma causa e a segunda é neutra e tem como objetivo particular apenas a descoberta da verdade. Segundo Nicholls (2004), essa distinção é importante e ajuda a esclarecer a compreensão pouco consensual desse conceito e as ambigüidades e indefinições relacionadas ao conceito de scholarship da docência (PAULSEN; FELDMAN, 1995).

A scholarship polêmica tende a pesquisar textos. Ela busca a evidência prioritariamente dentro da própria disciplina e raramente extrapola a disciplina, pois espera encontrar todas as respostas a qualquer questão levantada dentro 
dos próprios textos disciplinares. Pode-se dizer que a scholarship polêmica é introspectiva e relativamente simplista em sua abordagem das questões. Por outro lado, a scholarship acadêmica permite a busca de explanações mediante a exploração de todos os ângulos, mas especialmente de áreas externas ao campo imediato.

Baseado fortemente no trabalho anterior de Lynton e Elman (1987), Shulman (1987) e outros autores, Boyer publicou em 1990 o relatório Scholarship Reconsidered onde abriu um vigoroso debate sobre o trabalho acadêmico do docente universitário e as atividades que são valorizadas para fins de promoção na carreira acadêmica. Com esse relatório, foi um dos primeiros a chamar a atenção para o conceito restrito e unidimensional de scholarship mantido pela profissão acadêmica. A propósito, escreve Boyer (1990, p. 36):

Scholarship não é um apêndice esotérico; ela está no coração do que é a profissão. Todos os docentes, ao longo de suas carreiras, devem permanecer estudantes. Como scholars, devem continuar a aprender e a se engajar séria e continuamente na expansão do mundo intelectual. Isso é essencial à vitalidade e vigor da graduação.

Boyer constata que, embora a comunidade acadêmica tradicionalmente considere os três componentes de seu trabalho - scholarship (pesquisa), docência e serviço - como relacionados, para muitos propósitos ela os trata como separados. Assim, quando um docente é avaliado para promoção, cada um dos três componentes é avaliado separadamente. Ele considera enganosa essa divisão da vida profissional do acadêmico e entende que este é acima de tudo e talvez exclusivamente um scholar. No entanto, defende que a idéia de scholarship não está associada apenas à pesquisa e à atividade criativa, mas está incluída em todos os papéis tradicionais de um acadêmico.

Boyer identificou quatro papéis chaves na scholarship acadêmica: descoberta, integração, aplicação e docência. Embora tenha reconhecido essa diferenciação de papéis docentes, Boyer (1990, p. 25) adverte:

Reconhecemos que estas quatro - a scholarship da descoberta, da integração, da aplicação e da docência - dividem as funções intelectuais que estão ligadas inseparavelmente entre si. No entanto ainda vale a pena, acredito, analisar os vários tipos de trabalho acadêmico, e ao mesmo tempo reconhecer que interagem de forma dinâmica, formando um todo independente.

Eugene Rice $(1991,1992)$, como Boyer, ex-membro da famosa Carnegie Foundation, vê as quatro dimensões da scholarship como correspondentes a 
abordagens distintas da percepção e do processamento do conhecimento - nomeadamente, o avanço, a aplicação, a integração e a representação do conhecimento. Essa proposta de Boyer possibilitou a consideração de scholarship num contexto mais amplo, permitindo vê-la como um todo inter-relacionado com componentes distintos e diferentes abordagens do conhecimento.

A primeira forma de scholarship de Boyer é a scholarship da descoberta, a qual se relaciona à descoberta de novos conhecimentos ou à criação de novas formas artísticas. A scholarship da descoberta identifica-se com a missão tradicional da atividade de pesquisa pura, de pesquisa original, de busca do conhecimento por si mesmo, de avanço do conhecimento especializado. Boyer enfatizou que a scholarship da descoberta, ou pesquisa, é um "processo penetrante de excitação intelectual" mais do que uma simples preocupação com os resultados na forma de novo conhecimento.

A scholarship da integração relaciona-se à interpretação dada a novos dados emergentes ou a formas artísticas na medida em que se integram com outros resultados e se comparam com outras criações. A própria expansão da especialização requer novas formas de integração. Sem um contínuo esforço de integração, tem-se a fragmentação. A integração possibilita a articulação entre conhecimentos e modelos de diferentes disciplinas e requer um tipo diferente de abordagem do conhecimento. Há necessidade de scholars, com a capacidade de síntese, para buscarem novas relações entre as partes e o todo, relacionarem o passado e o futuro ao presente e deslindarem padrões de significado que não se enquadram na perspectiva disciplinar tradicional. A scholarship da integração busca realizar a síntese dos conhecimentos de modos criativos, fazendo a ponte entre campos ou disciplinas e desvendando novos significados para os conhecimentos anteriormente desconectados.

A scholarship da aplicação ou da prática é definida como a aplicação do conhecimento aos problemas e situações práticas do mundo real de uma maneira racional. Como uma atividade profissional na prática e no serviço, ela precisa ser avaliada com o rigor semelhante ao da pesquisa e da docência. Mesmo antes de Boyer, Ernest Lynton e Sandra Elman (1987) já haviam mostrado a necessidade de que novos conhecimentos precisam ser interpretados, disseminados e aplicados à solução dos problemas da sociedade. Na obra New Priorities for the University, apelam para uma renovada ênfase na 'scholarship da aplicação, do serviço público ou da prática, a qual inclui o envolvimento do corpo docente "nas aplicações externas do conhecimento mediante a assistência técnica, análise de política e outras atividades de extensão" (LYNTON; ELMAN, 1987, p. 7). Também Donald Schön (1983, p. viii), na obra The Reflective Practitioner, 
descreve uma nova "epistemologia da prática" baseada nos modos como o conhecimento é construído quando se está engajado nas atividades de serviço ou prática profissional. Já existe um reconhecimento emergente da legitimidade de outro tipo de conhecimento - o conhecimento emergente da prática. A visão dominante de scholarship coloca a pesquisa e a teoria em posição hierarquicamente superior à prática. Esta tem sido considerada o recipiente passivo do conhecimento desenvolvido. A visão alternativa sustenta que em muitos campos aplicados o conhecimento emerge da complexidade e do rigor da prática. Em vez de uma relação hierárquica, essa visão defende que teoria e prática são complementares e mutuamente enriquecedoras (CURRY et al., 1993). Esta forma de scholarship se relaciona mais diretamente com o trabalho do corpo docente das faculdades profissionais.

Finalmente, existe a scholarship da docência que, segundo Boyer, tem sua integridade própria, mas está profundamente imbricada com as outras três formas. A scholarship da docência e do ensino consiste na compreensão da transação ensino-aprendizagem, tanto em relação a seu processo como a seu resultado, e tem três elementos distintos: primeiro, uma capacidade sinóptica, ou seja, a habilidade para extrair os aspectos essenciais de um campo de modo a lhe fornecer coerência e significado, para colocar em contexto o que é conhecido e abrir o caminho para conexões a serem feitas entre o cognoscente e o conhecido; segundo, o que Shulman (1987) chama de conhecimento do conteúdo pedagógico, entendido como a capacidade de representar um conteúdo num modo que transcenda a separação entre substância intelectual e processo didático, geralmente tendo a ver com as metáforas, analogias e experimentos usados; e terceiro, conhecimento sobre aprendizagem, resultante das pesquisas sobre como os alunos fazem sentido do que os professores dizem e fazem. Essa concepção de scholarship da docência proposta por Boyer sugere que os acadêmicos devem abordar academicamente a docência, refletindo sobre o conhecimento obtido na pesquisa educacional em relação aos contextos particulares nos quais ensinam, enfatizando a importante relação recíproca existente entre teoria e prática e valorizando o conhecimento dos práticos obtido a partir da experiência. Apesar deste esclarecimento básico do conceito de scholarship da docência prestado por Boyer, a década de noventa apresentou um interesse crescente pela noção e re-interpretação deste conceito, levando a entendimentos e implicações não consideradas anteriormente (KEMBER, 1997; KREBER, 1999, 2000, 2002b; KREBER; CRANTON, 2000; TRIGWELL et al., 2000).

Esse modelo quadri-dimensional de scholarship, desenvolvido por Boyer e Rice, já trouxe contribuição significativa, acessível e altamente produtiva 
para a reconceptualização de scholarship. Atualmente, seu modelo está sendo usado pelo National Project on Institutional Priorities and Faculty Rewards para engajar um número de sociedades científicas na formulação de princípios que reconceptualizem a scholarship em suas próprias disciplinas (DIAMOND, 1994). Práticas semelhantes já podem ser encontradas no Canadá e na Austrália (CUNSOLO et al., 1996; THE UNIVERSITY OF MELBOURNE, 2002).

Partindo de uma perspectiva dedutiva e, baseados no paradigma das quatro dimensões funcionais da ação em sistemas sociais, econômicos, evolucionários e educacionais, desenvolvidos por Talcott Parsons (1956) e Parsons e Platt (1973), Paulsen e Feldman (1995) propõem um modelo quadri-dimensional de scholarship. A aplicação do paradigma das quatro funções ao sistema de ação da scholarship sugere que (1) a função de manutenção de padrão é exercida pelas ações que constituem o subsistema de scholarship da pesquisa e da pós-graduação; (2) a função de adaptação é desempenhada pelas ações constitutivas do subsistema de scholarship da docência; (3) a função de alcance das finalidades é exercida pelo subsistema de scholarship do serviço; e (4) a função de integração é desempenhada pelas ações constitutivas do subsistema de scholarship da cidadania acadêmica. Estes quatro subsistemas podem ser interpretados como representando as dimensões conceituais básicas do construto da scholarship e são apresentados de modo sucinto na Figura 1. Em três das quatro dimensões da scholarship, o modelo de Paulsen e Feldman coincide com o proposto por Boyer e Rice. A Figura 2 apresenta exemplos de atividades concretas do corpo docente em cada um dos quatro subsistemas funcionais. As atividades classificadas nesta figura são extraídas de pesquisas identificadas em três estudos inferenciais relativamente recentes das várias dimensões da scholarship (BRAXTON; TOOMS, 1982; PELLINO et al., 1984; SUNDRE, 1992).

Doze anos após a publicação de Scholarship Reconsidered, Rice (2002) escreveu um artigo intitulado Beyond Scholarship Reconsidered, onde descreveu os desdobramentos ocorridos especialmente na scholarship da docência e na scholarship da aplicação, renomeada esta última para scholarship do engajamento.

A scholarship do engajamento agora proposta fundamenta-se no importante trabalho de Ernest Lynton (1995) e Driscoll e Lynton (1999). Essas contribuições aprimoraram a habilidade para documentar e promover o reconhecimento do trabalho docente na aplicação do conhecimento. Ao propor a scholarship do engajamento, os docentes comprometidos com este trabalho não estão apenas restaurando a "extensão", como no caso das universidades land-grant com suas raízes agrícolas, ou a função de "serviço". Antes, o que está sendo 
enfatizado é a colaboração. O ensino e a aprendizagem serão multidirecionais e a competência será partilhada. Isso representa uma reconceptualização básica do envolvimento do corpo docente no trabalho baseado na comunidade e vai requerer um esforço concertado entre disciplinas e setores institucionais. Isso irá também envolver a participação de membros representativos da comunidade no planejamento e discussão desde o começo.

Importante para o desenvolvimento da scholarship do engajamento foi o trabalho de Donald Schön (1983) sobre "o prático reflexivo". Ele foi um líder ativo na reconsideração da scholarship e seu argumento de que "a nova scholarship requer uma nova epistemologia" (1995, p. 27) continua muito influente. Schön tem argumentado que as universidades desenvolvem uma "epistemologia institucional" (p. 34) que tem colocado a prática em relação à teoria e à pesquisa numa situação hierarquicamente secundária e derivativa e essa teoria do conhecimento está concretizada nas estruturas e práticas institucionais, especialmente no sistema de recompensas e de promoção dos docentes.

O trabalho mais recente de Driscoll e Lynton (1999) sobre a scholarship do engajamento propõe três componentes, que são paralelos aos três elementos tradicionais do trabalho docente: ensino, pesquisa e serviço. São eles: pedagogia engajada, pesquisa baseada na comunidade e prática colaborativa (RICE, 2002).

Quanto à pedagogia engajada, observa-se que as dimensões pedagógicas da scholarship do engajamento requerem uma abordagem radicalmente diferente do ensino e da aprendizagem. Em pedagogias engajadas, como aprendizagem-serviço e comunidades aprendentes, a aprendizagem efetiva é contextual e social. Nesse novo contexto de ensino-aprendizagem, o corpo docente precisa repensar suas relações com os estudantes e muitas de suas pressuposições fundamentais sobre ensino.

Na pesquisa baseada na comunidade, a scholarship do engajamento requer o realinhamento do conhecimento local e cosmopolitano. A pesquisa pura, ou seja, objetiva, abstrata e analítica, é altamente valorizada e tem legitimidade porque pode ser avaliada por pares da comunidade acadêmica, independentemente de lugar. A pesquisa baseada na comunidade é necessariamente local, enraizada num tempo e contexto particular. Os pares mais competentes poderão ser representantes da comunidade local e não da academia. A pesquisa baseada na comunidade requer competência partilhada e desafia os critérios acadêmicos estabelecidos. Ela também precisa ser colaborativa e requer que a aprendizagem seja multidirecional e não centrada na universidade.

Num momento histórico em que as comunidades locais são desafiadas a aprimorar suas capacidades e as universidades devem demonstrar sua pres- 
tação de contas pública, a pesquisa baseada na comunidade é um modo tanto para fortalecer a capacidade da comunidade como para responder à responsabilidade cívica das instituições universitárias. Em contraste com a prática de pesquisa junto à comunidade no passado, na qual os membros da comunidade eram simplesmente "sujeitos passivos" e recipientes passivos da informação, a pesquisa baseada na comunidade ou pesquisa participante, como às vezes é chamada, valoriza a perspectiva da comunidade local e traz para ela cada fase do processo de pesquisa.

Figura 1- O sistema de ação da scholarship

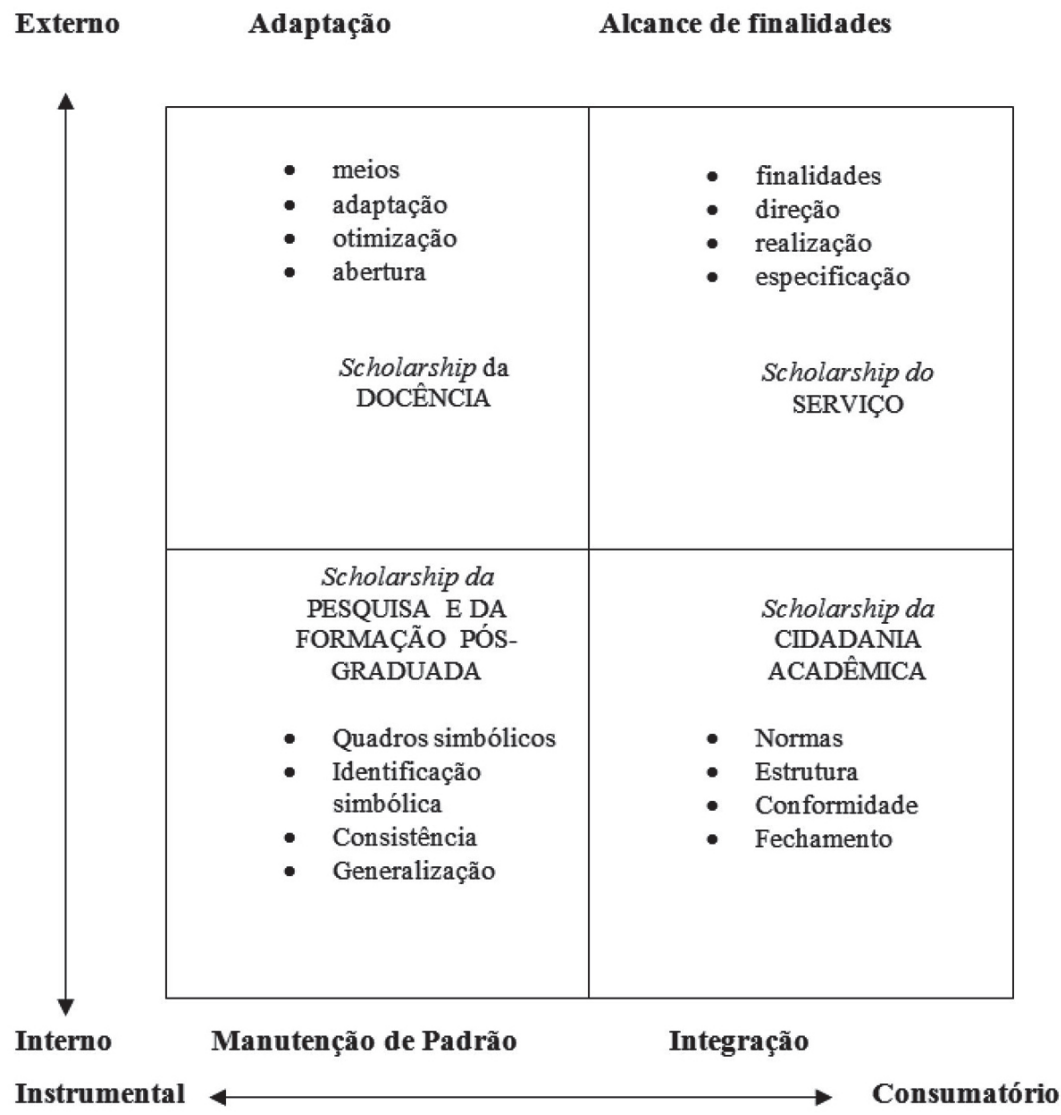

Fonte: PAULSEN, Michael B.; FELDMAN, Kenneth Towards a reconceptualisation of scholarship: A human action system with functional imperatives. Journal of Higher Education, Columbus (Ohio), v. 66, n. 6, p. 615-641, 1995. 


\section{Figura 2 - Classificação das atividades docentes nos subsistemas de ação da scholarship}

Scholarship da Docência

Scholarship do Serviço

- mostra estilo docente criativo*

- pesquisa abordagens inovadoras de ensino*

- faz apresentações aos colegas sobre novas técnicas instrucionais**

- prepara materiais instrucionais interessantes*

- desenvolve e ensina novos cursos*

- engaja-se em consulta extra-campus***

- conduz seminários para leigos sobre tópicos disciplinares atuais****

- conduz estudos para agências governamentais locais****

- fornece testemunha expert *

- contribui para aplicações tecnológicas no campo *

- conduz pesquisas regularmente*

- apresenta trabalhos em encontros profissionais e acadêmicos*

- publica em revistas com referees*

- ensina na pós-graduação*

- orienta projetos de pesquisa de pósgraduandos*
- participa em revisão por pares*

- é ativo em organizações profissionais ou baseadas em disciplina*

- exerce um papel importante na revisão curricular de sua unidade ${ }^{* * *}$

- $\quad$ serve em equipes de credenciamento**

- conduz um estudo para ajudar a resolver um problema departamental****

Scholarship da Pesquisa e da Formação Pós-graduada

Scholarship da Cidadania acadêmica

Nota: * (SUNDRE, 1992) ** (PELLINO et al., 1984); *** (BRAXTON; TOOMS, 1982).

Fonte: Paulsen; Feldman (1995).

O trabalho no terceiro componente da scholarship do engajamento - a prática colaborativa - começa por levar em conta seriamente o que Ira Harkavy, da Universidade de Pensylvannia, e outros chamaram de Princípio de Noé: "Não mais prêmios para prever a chuva. Prêmios somente para construir a arca". O foco aqui é nos problemas baseados na comunidade, problemas concretos e quase sempre adiados (RICE, 2002). 


\section{Scholarship da docência}

Desde que Boyer (1990) e Rice (1991) introduziram a noção de scholarship da docência, seu significado preciso, implicações (MENGES; WEIMER, 1996) e avaliação (GLASSICK; HUBER; MAEROFF, 1997) continuam não plenamente resolvidos. No entanto, durante este período tem aparecido uma crescente literatura sobre o tema procurando esclarecer, expandir, operacionalizar e avaliar a utilidade e aplicação do conceito (CUNSOLO et al., 1996; KREBER; CRANTON, 1997; MENGES; WEIMER, 1996; MOREHEAD; SHEDD, 1996; PAULSEN; FELDMAN, 1995). Baseados nessa literatura, dois estudos principais têm tentado recentemente contextualizar a scholarship da docência (TRIGWELL et al., 2000; KREBER, 2000b).

Trigwell et al. (2000) sugerem que há cinco interpretações hierárquicas e qualitativamente diferentes de scholarship da docência que vão do que o professor faz para um foco na aprendizagem do aluno. De acordo com Trigwell et al., elas diferem em quatro dimensões: informação, reflexão, comunicação e concepções de ensino. Essas quatro dimensões podem ser assim sumarizadas: a fonte de informação na qual se baseiam os professores, o foco de sua reflexão, a natureza e extensão de sua comunicação de insights e suas concepções de ensino e aprendizagem. O modelo formulado sugere que o engajamento em atividades de ordem superior dentro da scholarship da docência requer que os acadêmicos: consultem a literatura científica especializada sobre ensino e aprendizagem; focalizem a reflexão nas áreas específicas de sua própria prática, focalizem a docência nos estudantes e na aprendizagem; e publiquem os resultados das iniciativas docentes mediante mecanismos de avaliação por pares. Assim, os docentes podem se engajar na scholarship da docência em graus variados.

Kreber (2002a) distingue quatro perspectivas sobre a scholarship da docência. A primeira perspectiva é paralela à concepção tradicional de scholarship como pesquisa de descoberta. Neste caso, o docente realiza pesquisa e cria produtos visíveis, como artigos, livros e apresentações de conferências sobre ensino (HEALY, 2000; RICHLIN, 2001). Essa perspectiva é semelhante à visão de scholarship da docência proposta por Boyer (1990) e Rice (1991), já explicitadas anteriormente. Para os proponentes desta perspectiva, a efetividade docente é inferida do produto que é criado, sendo este o indicador de scholarship. No entanto, esta inferência é mais presumida do que comprovada.

Na segunda perspectiva, a scholarship da docência é praticada por docentes excelentes e assim scholarship é igual a excelência, como fica evidenciado por prêmios a docentes ou por avaliações destacadas da docência (MOREHEAD; 
SHEDD, 1996). A pressuposição subjacente a esta perspectiva é que docentes excelentes - assim identificados por avaliações de estudantes ou por avaliações por pares - possuem extenso conhecimento sobre ensino e aprendizagem. $\mathrm{O}$ desenvolvimento da scholarship na docência envolve a reflexão docente sobre o conhecimento baseado em pesquisa e sobre o conhecimento baseado em sua própria experiência (MENGES; WEIMER, 1996). No entanto, possuindo apenas conhecimentos implícitos baseados na experiência, docentes excelentes podem ser incapazes de articular o que fazem em termos educacionais.

Mais recentemente surgiu uma terceira perspectiva que procurou adotar uma abordagem acadêmica da docência mediante a aplicação da teoria e da pesquisa educacional à prática docente (MENGES; WEIMER, 1996). Aqui uma sabedoria da prática se desenvolve mediante a combinação da reflexão sobre a teoria e a pesquisa e sobre o conhecimento baseado na experiência em relação ao ensino ou docência.

A quarta perspectiva, inspirada na contribuição de Schön, propõe que a scholarship da docência se efetiva mediante o conhecimento baseado na experiência do docente. Esse conhecimento tácito sobre problemas e situações concretos não tratados nem resolvidos diretamente pela teoria e pela pesquisa é construído mediante a reflexão sobre a prática cotidiana do trabalho docente. Nesta nova perspectiva epistemológica, é a própria prática acompanhada pela reflexão que é fonte de novos conhecimentos e de solução dos problemas.

Todas as quatro perspectivas trazem uma importante contribuição para a compreensão da scholarship da docência. No entanto, a primeira e a segunda perspectiva, ao enfatizarem resultados ou produtos na forma de publicações ou avaliações da docência, podem estar ignorando o processo pelo qual o docente aprende sobre ensino (KREBER, 1999; KREBER, 2000). Uma concepção de scholarship da docência que inclui a demonstração de conhecimento sobre ensino, mas desconsidera o processo como esse conhecimento é adquirido, é válida, mas de pouca utilidade para ajudar o docente a desenvolver sua prática (KREBER; CRANTON, 2000).

A terceira perspectiva, embora inadvertidamente, implica que a scholarship da docência envolve a reflexão sobre e a aplicação do trabalho realizado pelos pesquisadores que se especializam em educação como uma disciplina científica. Embora isso seja importante, Kreber e Cranton (2000) sugerem que a scholarship da docência também inclui a aquisição de conhecimento sobre ensino mediante a reflexão sobre a prática e a pesquisa sobre o ensino na própria disciplina do docente. De modo semelhante que a primeira perspectiva, esta terceira também está menos preocupada com a questão de como a scholarship, 
pode ser demonstrada e avaliada. Kreber e Cranton (2000) defendem que a scholarship da docência inclui tanto a contínua aprendizagem sobre ensino como a demonstração de conhecimento sobre ensino. Ambas são de importância crítica para o desenvolvimento e a avaliação do corpo docente.

A última perspectiva, inspirada na epistemologia da prática de Schön, recupera o valor e a importância da prática no processo de criação de novos conhecimentos úteis para a solução de problemas práticos. O nível dos problemas concretos apresenta novidades e características que só de modo genérico e vago são captados pelas grandes teorias. Uma teoria da ação precisa ser construída mediante a reflexão sobre a ação, antes, durante e depois dela. Isso é feito pelo "profissional reflexivo" no cotidiano de suas atividades profissionais. No contexto docente, até mesmo o professor leigo em ciências da educação pode construir um saber docente baseado na sua experiência e prática docente.

Kreber (2002b) conclui sua síntese dessas diferentes perspectivas de entendimento da scholarship da docência, afirmando que "a scholarship da docência, apesar de seu longo apelo intuitivo para muitos, até o presente tem sido um conceito que carece de uma definição unificada" (p. 8). Os trabalhos de Trigwell et al. (2000) e de Kreber (2002b) sugerem que há necessidade de mais pesquisas no campo da scholarship da docência para que esta possa ter um significado claro, distinto e definido para a comunidade acadêmica.

\section{Efetivação da scholarship da docência}

As ambigüidades ainda remanescentes em relação ao conceito de scholarship da docência não têm impedido que ele seja progressivamente instituído nas universidades mediante políticas e práticas efetivas de estímulo e apoio à sua implementação. Esse movimento é particularmente significativo em universidades norte-americanas, canadenses e australianas. Lee Shulman, como novo presidente da Carnegie Foundation for the Advancement of Teaching, em substituição ao falecido Ernest Boyer, vem promovendo iniciativas que estão estimulando e operacionalizando a prática efetiva da scholarship da docência nas universidades e nas associações científicas.

No Brasil, pequenas ações governamentais de estímulo à docência universitária tenderam a ser pontuais e não chegaram a induzir nas universidades a cultura da valorização acadêmica da docência. Até o presente, em poucas faculdades foram criados núcleos de apoio e suporte didático aos docentes. Além disso, a criação e consolidação relativamente recente da pós-graduação nas universidades brasileiras levaram os docentes com formação avançada a 
privilegiar a pós-graduação e a relegar a graduação aos docentes mais jovens e menos titulados. Assim, a graduação passou a sofrer crescente desprestígio e desconsideração pelos docentes mais experientes e preparados. Essa dupla situação histórica tem criado uma cultura de desqualificação técnica e de desprestígio social da função docente do profissional acadêmico brasileiro que leciona nos cursos de graduação. Constituiu-se nas universidades federais brasileiras, como constatou Edmundo Coelho (1988) na década de oitenta, uma dupla "casta": a do "baixo clero", formada por docentes da graduação, e a do "alto clero", constituída pelos docentes da pós-graduação. Estes, valorizados e cercados de privilégios, aqueles, sobrecarregados de aulas e carentes de suporte pedagógico-instrucional. Mais recentemente, Balbachevsky (1999), em pesquisa analisando a atitude de professores universitários brasileiros em relação à pesquisa e à docência, constatou a persistência do desprestígio e, em conseqüência, a desvalorização da docência nas universidades brasileiras.

A relativa precariedade da experiência brasileira em relação à valorização da nova scholarship da docência requer que levemos em conta, com mais cuidado, as práticas eficazes e bem sucedidas de universidades do Primeiro Mundo a esse respeito. $\mathrm{O}$ aprendizado e a adaptação da experiência alheia ao contexto nacional podem ajudar a acelerar a solução dos problemas de qualidade de nossa educação superior.

Kenneth Zahorski (2002), numa abordagem sinergística, propõe uma estratégia para criar um programa gestáltico ou holístico de ambiência para o cultivo da scholarship da docência e lista alguns benefícios derivados dessa estratégia holística.

A criação de uma cultura acadêmica que nutre e apóia a scholarship não é fácil, mas abordada com energia, determinação e sensibilidade, pode ser instalada. Para isso, Zahorski indica alguns pré-requisitos para a criação de tal ambiência.

a) Criação de um programa holístico de desenvolvimento docente

O programa de desenvolvimento docente com maior chance de criar uma gestalt transformadora é aquele que lança sua rede longe, incorporando oportunidades tanto para o desenvolvimento instrucional como para o desenvolvimento organizacional e pessoal. O Programa de Desenvolvimento Docente do St. Norbert College apresenta os componentes típicos da maioria dos programas holísticos: (1) Centro de recursos, (2) programa de orientação e tutoria de novos docentes, (3) programa de mini-bolsa, (4) programas sabáticos e de afastamento, (5) conferência anual de desenvolvimento docente, (6) 
encontros e workshops temáticos, (7) séries de discussão na hora do almoço, (8) programa de docente visitante, (9) folheto (newsletter), (10) publicação de debates em livro, (11) membro de rede regional de desenvolvimento docente, (12) fundo para participação em eventos, (13) programa de preparação para a aposentadoria, (14) prêmios para excelência em docência, pesquisa e serviço, (15) programa de visiting scholars (pós-doutorado/professor visitante), e (16) aconselhamento individual. Em geral, os programas holísticos têm um diretor ou coordenador com disponibilidade de tempo e uma comissão de desenvolvimento docente que monitora as necessidades dos docentes e administra as atividades de desenvolvimento docente.

b) Desenvolvimento docente na instituição como um todo

Embora a responsabilidade principal do desenvolvimento docente seja do Programa de Desenvolvimento Docente, a geração de uma ambiência institucional demanda o compromisso e a participação de toda a comunidade acadêmica, especialmente das pessoas em posição de chefia e administração que, pelas suas próprias posições já devem naturalmente exercer o papel de agentes de desenvolvimento.

c) Agentes de desenvolvimento docente como antropólogos e agentes de mudança

Para oferecer sugestões construtivas de mudança, o agente de desenvolvimento docente precisa conhecer intimamente a instituição, de modo semelhante a um habilidoso antropólogo que conhece uma cultura mediante cuidadosa observação e estudo. Para isso, precisa conhecer o catálogo da instituição, os estatutos, regulamentos e normas que regem a vida dos docentes, materiais sobre desenvolvimento docente de outras instituições, serviços de mídia e computadores. Deve ainda estudar a estrutura organizacional da instituição. Em suma, o profissional responsável pelo desenvolvimento docente, na esperança de gerar impacto como agente de mudança, deve aprender a se movimentar nos labirintos da estrutura organizacional da instituição com agilidade e confiança, a fim de assegurar a eficácia de suas ações no programa de desenvolvimento docente (ZAHORSKI, 1993).

d) Construtor de ponte

Uma cultura institucional terá mais chance de eficácia se seus sistemas de apoio não forem fragmentários. O programa de desenvolvimento docente deve fornecer cultivo, orientação e apoio do começo ao fim do processo. 
e) Prática da arte do encorajamento

É criticamente importante que todos os profissionais envolvidos com o desenvolvimento docente, do diretor do Programa de Desenvolvimento Docente aos chefes de departamento e aos diretores de faculdades, sejam encorajadores e estimuladores. Como enfatiza Marsha Sinetar na sua obra The Mentor's Spirit (1998), como conselheiros, mentores e facilitadores, devemos todos tornar-nos "artistas do encorajamento" (p. 25). Os pequenos gestos de encorajamento reforçam a cultura de apoio à scholarship da docência, reenergizando tanto o docente como a instituição.

Muitos benefícios derivam da criação de uma cultura de estímulo e apoio à scholarship. $\mathrm{O}$ primeiro deles é evidentemente um nível mais alto de produtividade acadêmica. Mas há outros não tão tangíveis como a produtividade, mas, a seu modo, também significativos. Primeiro, no modelo sinergístico, uma secretaria ou coordenação de desenvolvimento docente torna-se uma força institucional potente por causa do impacto adicional e visibilidade, ganhos com as alianças costuradas com outras unidades institucionais. Segundo, mediante as ligações intra-institucionais e as parcerias características da abordagem sinergística, pontes mais fortes são construídas entre o desenvolvimento docente e outras unidades institucionais. Colaboração mais intensa leva a maior comunicação e à revitalização do espírito de comunidade e colegialidade. Terceiro, mediante a abordagem sinergística, acentua-se a importância de outros agentes de desenvolvimento profissional. A consciência de que o crescimento profissional é tarefa de todos pode levar a uma mudança mais positiva no campus da universidade. Finalmente, cabe lembrar que a abordagem sinergística ajuda a criar um ambiente de esperança e oportunidade para a consolidação efetiva da scholarship da docência.

\section{Palavras conclusivas}

As múltiplas funções do docente universitário, parcialmente como expressão das já convencionais funções da universidade e parcialmente como manifestação de novos papéis da universidade em um novo momento histórico, precisam ser valorizadas pela universidade e pela sociedade para serem efetivamente exercidas, o que não significa que todo professor as deva desempenhar de modo igualmente competente e com igual dedicação. Cada docente, em razão de sua competência, opção e gosto, poderá privilegiar alguma ou algumas de suas múltiplas funções e em relação a ela(s) ser avaliado e promovido. Com 
uma política que valoriza todas suas funções, a universidade poderá assegurar excelência de seus docentes em todas e reconhecimento e promoção do mérito dessa excelência. $\mathrm{O}$ docente que tiver especial apreço pelo ensino e formação de jovens nos cursos de graduação terá seu trabalho estimulado, valorizado e reconhecido. O que possuir especial dote para a pesquisa, poderá privilegiá-la para avançar o conhecimento em sua área de interesse. Aquele que tiver particular capacidade de síntese escreverá e publicará livros-textos e de sistematização dos conhecimentos mais recentes em sua área de competência. Quem for capaz de traduzir os conhecimentos científicos sofisticados em linguagem simples e compreensível para leigos de instrução média escreverá livros para divulgação mais ampla da cultura científica e/ou literária na sociedade. Aquele professor que tiver interesse e competência especial na aplicação dos conhecimentos em sua área priorizará seu envolvimento com o mundo do trabalho. Essa valorização institucional das várias funções docentes torna-se possível, aceitável e legítima em decorrência da expansão do conceito de scholarship.

De modo especial a scholarship da docência se beneficiará de sua valorização. Além da valorização da excelência na docência, a pesquisa sobre a própria docência será um fator de contínuo aprimoramento do trabalho docente, levando em consequência à melhoria da qualidade do ensino e da formação das novas gerações de jovens que passam pela universidade. A capacitação permanente em relação à própria prática docente e a pesquisa teórico-prática sobre a própria prática serão o instrumento mais eficaz do aprimoramento da própria prática docente.

Em suma, o exercício das múltiplas funções do professor universitário, além de possibilitar o melhor desempenho de cada docente em suas áreas de interesse acadêmico, será uma condição essencial para que a universidade devolva à sociedade pessoas com ampla cultura, formadas com uma perspectiva humanista e cidadã e preparadas como profissionais competentes.

\section{Referências}

BALBACHEVSKY, Elizabeth. A profissão acadêmica no Brasil. Brasília: FUNADESP, 1999.

BOYER, Ernest. Scholarship reconsidered: priorities of the professoriate. Princeton, NJ: Carnegie Foundation for the Advancement of Teaching, 1990. 
BRAXTON, John M.; TOOMBS, William. Faculty uses of doctoral training: Consideration of a technique for the differentiation of scholarly effort from research activity. Research in Higher Education, New York, v. 16, n. 3, p. 265-82, sept. 1982 .

COELHO, Edmundo C. Sinecura acadêmica: a ética universitária em questão. São Paulo: Revista dos Tribunais, 1988.

CUNSOLO, Joe et al. The scholarship of teaching: A Canadian perspective with examples. The Canadian Journal of Higher Education, Ottawa, v. 26, n. 1, p. 35-56, 1996.

CURRY, Lynn et al. Educating professionals: Responding to new expectations for competence and accountability. San Francisco: JosseyBass, 1993.

DIAMOND, Robert M. The tough task of reforming the faculty-rewards system. Chronicle of Higher Education, Washington, D.C., v. 40, p. B1-B3, may. 1994.

DRISCOLL, Amy; LYNTON, Ernest. Making outreach visible: A guide to documenting professional service and outreach. Washington, DC: American Association for Higher Education, 1999.

GLASSICK, Charles E.; HUBER, Mary T.; MAEROFF, Gene I.

Scholarship Assessed: Evaluation of the professoriate. San Francisco: Jossey-Bass, 1997.

HEALY, Mick. Developing the scholarship of teaching in higher education: A discipline-based approach. Higher Education Research and Development, Oxford, v. 19, n. 2, p. 169-189, July 2000.

KEMBER, David. A reconceptualization of the research into university academics' conceptions of teaching. Learning and Instruction, Louvain, n. 7, n. 3, p. 255-275, sept. 1997.

KREBER, Carolin. A course-based approach to the development of teachingscholarship: A case study. Teaching in Higher Education, Oxford, v. 4, n. 3, p. 309-325, jul. 1999.

KREBER, Carolin. How university teaching award winners conceptualize academic work: Some further thoughts on the meaning of scholarship. Teaching in Higher Education, Oxford, v. 5, n. 1, p. 61-78, jan. 2000. 
KREBER, Carolin. Controversy and consensus on the scholarship of teaching. Studies in Higher Education, Oxford, v. 27, n. 2, p. 151-167, may. 2002a.

KREBER, Carolin. The scholarship of teaching: A comparison of conceptions held by experts and regular academic staff. Edmonton: University of Alberta Press, 2000b.

KREBER, Carolin; CRANTON, Patricia. A. Teaching as scholarship: A model for instructional development. Issues and Inquiry in College Learning and Teaching, Ypsilanti (Michigan), v. 19, n. 2, p. 4-13, 1997. KREBER, Carolin; CRANTON, Patricia. A. Exploring the scholarship of teaching. Journal of Higher Education, Columbus (Ohio), n. 71, v. 4, p. 476-495, jul./aug. 2000.

LYNTON, Ernest. Making a case for professional service. Washington, DC: American Association for Higher Education, 1995.

LYNTON, Ernest; ELMAN, Sandra E. New priorities for the university. San Francisco: Jossey-Bass, 1987.

MENGES, Robert J.; WEIMER, Marylleen. Teaching on solid ground: Using scholarship to improve practice. San Francisco (CA): Jossey-Bass, 1996.

MOREHEAD, Jere M.; SHEDD, Peter J. Students' interviews: A vital role in the scholarship of teaching. Innovative Higher Education, New York, v. 20, n. 4, p. 261-269, Summer, 1996.

NICHOLLS, Gill Scholarship in teaching as a core professional value: What does this mean to the academic? Teaching in Higher Education, Oxford, v. 9, n. 1, p. 29-42, jan. 2004.

PARSONS, Talcott. Societies: evolutionary and comparative perspectives. Englewood Cliffs, NJ: Prentice-Hall, 1956.

PARSONS, Talcott; PLATT, George M. The American University. Cambridge (Mass.): Harvard University Press, 1973.

PAULSEN, Michael B.; FELDMAN, Kenneth Towards a reconceptualisation of scholarship: A human action system with functional imperatives. Journal of Higher Education, Columbus (Ohio), v. 66, n. 6, p. 615-641, 1995. 
PELLINO, Glenn R. et al. The dimensions of academic scholarship: Faculty and administrator views. Research in Higher Education, New York, v. 20, n. 1, p. 103-115, 1984.

RICE, R. Eugene. The new American scholar: Scholarship and the purposes of the university. Metropolitan Universities Journal, Boston (Mass), v. 1, n. 4, p. 7-18, 1991.

RICE, R. Eugene. Toward a broader conception of scholarship: The American context. In: WHISTON, T. G.; GEIGER, R. L. (Eds.). Research and Higher Education in the United Kingdom and the United States. Lancaster, England: Society for Research into Higher Education, 1992.

RICE, R. Eugene. Beyond Scholarship Reconsidered: Toward an enlarged vision of the scholarly work of faculty members. New Directions for Teaching and Learning, San Francisco, n. 90, p. 7-17, 2002.

RICHLIN, Laurie. Scholarly teaching and the scholarship of teaching. New Directions for Teaching and Learning, San Francisco, n. 86, p. 57-68, 2001.

RUDOLPH, Frederick. The American College and University: a history. New York: Vintage Books, 1962.

SCHÖN, Donald. The reflective practiotioner. New York: Basic Books, 1983.

SCHÖN, Donald. The new scholarship requires a new epistemology.

Change, Oxford, v. 27, n. 6, p. 26-34, nov./dec. 1995.

SEVERINO, Antônio J. Expansão do ensino superior: contextos, desafios, possibilidades. Avaliação, Sorocaba, v. 14, n. 2, p.253-266, jul. 2009.

SHULMAN, Lee. S. Knowledge and teaching. Harvard Educational Review, Cambridge (Mas.), v. 57, n. 1, p. 1-22, feb. 1987.

SHULMAN, Lee. S. Course anatomy: The dissection and analysis of knowledge through teaching. In: HUTCHINGS, P. (Ed.). The course portfolio. Washington, DC: American Association for Higher Education, 1998.

SINETAR, Marsha. The Mentor's Spirit: life lessons on leadership and the art of encouragement. New York: St. Martin's Press, 1998. 
SUNDRE, Donna L. The specification of the content domain of faculty scholarship. Research in Higher Education, New York, v. 33, n. 3, p. $297-$ 315, jun. 1992.

TRIGWELL, Keith et al. Scholarship of teaching: A model. Higher Education Research and Development, Oxford, v. 19, n. 2, p. 155-168, jul. 2000.

THE UNIVERSITY OF MELBOURNE. Nine principles guiding teaching and learning in the University of Melbourne. Disponível em: <www.cshe. unimelb.edu.au/pdfs/9principles.pdf > Acesso em: julho 2009.

ZAHORSKI, Kenneth J. Taking the lead: Faculty development as institutional change agent. In: WRIGHT, D. L.; LUNDE, J. P. (Eds.). To improve the academy. Stillwater (Okla): New Forums Press, 1993. v. 12. ZAHORSKI, Kenneth J. Nurturing scholarship through holistic faculty development: A synergistic approach. New Directions for Teaching and Learning, San Francisco, n. 90, p. 29-37, Summer, 2002.

José Camilo dos Santos Filho - Universidade Estadual de Campinas Campinas | SP | Brasil. Contato: jcamilosantos@gmail.com

Carmen Lúcia Dias - Centro Universitário Metodista Presidente Prudente | SP | Brasil. Contato: kkaludias@gmail.com

Artigo recebido em 1 de junho de 2014 e aprovado em 8 de julho de 2014. 
